\title{
Use of chemotherapy at the end of life in Turkey
}

\author{
Sema Sezgin Goksu1*, Seyda Gunduz ${ }^{2}$, Dilek Unal ${ }^{3}$, Mukremin Uysal², Deniz Arslan², Ali M Tatlı', Hakan Bozcuk², \\ Mustafa Ozdogan² and Hasan S Coskun²
}

\begin{abstract}
Background: An increasing number of patients receive palliative chemotherapy near the end of life. The aim of this study is to evaluate the aggressiveness of chemotherapy in Turkish individuals near the end of life.

Methods: Patients diagnosed with solid tumors and died from 2010 to 2011 in the medical oncology department of Akdeniz University were included in the study. Data about the diagnosis, treatment details and imaging procedures were collected.

Results: Three hundred and seventy-three people with stage IV solid tumors died from 2010 to 2011 in our clinic. Eighty-nine patients (23.9\%) patients underwent chemotherapy in the last month of life while 39 patients (10.5\%) received chemotherapy in the last 14 days. The probability of undergoing chemotherapy in the last month of life was influenced by: age, 'newly diagnosed' patients, and performance status. There was no significant association of chemotherapy in the last month of life with gender and tumor type. Having a PET-CT scan did not alter the chemotherapy decision.

Conclusion: In conclusion, chemotherapy used in the last month of life in a tertiary care center of Turkey is high. Increasing quality of life should be a priority near the end of life and physicians should consider ceasing chemotherapy and direct the patient to early palliative care.
\end{abstract}

Keywords: Chemotherapy, End of life, Terminally ill, Cancer

\section{Background}

Chemotherapy plays an important role in the treatment of advanced cancer. Physicians offer patients chemotherapy not only as cure, but for symptom palliation and prolonging survival. Increasing number of patients receive palliative chemotherapy near the end of life [1,2]. Although there is evidence that the use of chemotherapy near the end of life is not related to its likelihood of providing benefit [3], medical decisions making on ceasing chemotherapy is very difficult since specific guidelines to help physicians with this topic are not available.

Inappropriate use of chemotherapy in the palliative setting may have negative consequences both for the patients and the health care system. Patients are faced with the risk of being administered a therapy, that may be toxic and potentially life-threatening, which may result in a poorer quality of life [4]. Despite the cost-effectiveness

\footnotetext{
* Correspondence: semasezgingoksu@gmail.com

${ }^{1}$ Kayseri State Hospital of Research and Education, Department of Medical Oncology, Kayseri, Turkey

Full list of author information is available at the end of the article
}

issue, 'the overuse' of chemotherapy at or near death is also a poor quality measurement of end of life care $[5,6]$.

High cost imaging modalities (CT: computerized tomography/MRI: magnetic resonance imaging /PET: positron emission tomography) are often used to determine the extent of disease, and may affect decisions about continuing or changing the treatment, or hospice referral at the end of life [7]. However Dinan et al. reported that high cost imaging is not correlated with the de-escalation of aggressive care [8].

Currently there are only a few palliative care units in Turkey $[9,10]$. Most of the hospitals, even the university cancer centers, do not have a palliative care unit and patients are treated by the medical oncologists until death. There are no hospices. To our knowledge, there is no data in the medical literature concerning chemotherapy usage at the end of life in the Turkey. So, we conducted a retrospective study to evaluate the aggressiveness of chemotherapy and its associates at the end of life in a tertiary cancer center in Turkey.

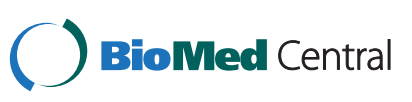

(c) 2014 Sezgin Goksu et al.; licensee BioMed Central Ltd. This is an Open Access article distributed under the terms of the Creative Commons Attribution License (http://creativecommons.org/licenses/by/4.0), which permits unrestricted use, distribution, and reproduction in any medium, provided the original work is properly credited. The Creative Commons Public Domain Dedication waiver (http://creativecommons.org/publicdomain/zero/1.0/) applies to the data made available in this article, unless otherwise stated. 


\section{Methods}

Patients diagnosed with solid tumors and died from 2010 to 2011 in the medical oncology department of Akdeniz University were included in the study. Akdeniz University is one of the biggest medical centers of the country, and we welcome many patients from the other cities. Like many other University hospitals in Turkey, our institution does not have a palliative care unit and patients are treated by the oncology team until death.

Patients with stage IV solid tumors and who died in the inpatient medical oncology clinics of Akdeniz University were included in the study. Hematologic malignancies that were treated in the hematology service ward were not included. The data collected for this study included demographic data, diagnosis, stage of the disease, whether chemotherapy was given, the time that the last course of chemotherapy was given, performance status at the time of chemotherapy, the time and duration of last hospitalization, imaging studies (CT, MRI, PET-CT), treatments, and the cause of death. Patients were described as 'newly diagnosed' if they had cancer diagnosis in the last 2 months of life. All the patients signed an informed consent about using their data with scientific purposes at the time of hospitalization.

Descriptive statistics methods were used for the statistical analysis of the data. The factors associated with chemotherapy at the end of life were analyzed using the multivariate logistic regression model in which we included (in a backward-Wald manner) all the significant variables from the univariate analysis. Mann-Whitney $\mathrm{U}$ test was used to compare the time between last chemotherapy and death between newly diagnosed and other patients. A p value of $<0.05$ was considered significant.

The study is approved by the Ethics Committee of Antalya Research and Training Hospital by reference number 2014-203.

\section{Results}

Three hundred and seventy-three people with solid tumors died from 2010 to 2011 in our clinic. The median age was 60 years (with a range of 20-90). We identified 133 patients $(35.7 \%) \geq 65$ years old and 240 patients $(64.3 \%)<65$ years old. There were 229 men (61.4\%), and 144 women (38.6\%). The most common diagnoses were non-small cell lung cancer $(25.5 \%)$, pancreas and biliary tract cancers (11.3\%), colon cancer (8.6\%), gastric-esophageal cancer (8.6\%), gynecologic cancers $(7.5 \%)$ and breast cancer (6.7\%). Seventy four (19.8\%) patients were 'newly diagnosed'. Eight-nine patients (23.9\%) underwent chemotherapy in the last month of life and 39 patients (10.5\%) were treated in the last 14 days (Table 1 ).

Univariate and multivariate analyses were performed to identify the factor(s) associated with chemotherapy at the end of life. Variables were classified as the most effective forms in the regression model. Three factors (age group, ECOG performance status, and newly diagnosis status) differed significantly between these groups $(\mathrm{p}<0.05)$ in univariate analysis. All of these significant variables in the univariate analysis were included in the multivariate logistic regression to analyze mortality risk (Table 2). The multivariate logistic regression analysis identified that chemotherapy at the end of life was significantly associated with age group, newly diagnose, and ECOG performance status. Probability of undergoing chemotherapy in the last month of life was influenced by: age (patients younger than 65 years were undergoing chemotherapy more often than those who were 65 years old or older), 'newly diagnosed' patients (patients diagnosed with cancer in the last two months of life were more likely to have chemotherapy), and ECOG performance status (patients with ECOG performance status $\leq 2$ were undergoing chemotherapy more often than those with ECOG performance status 3-4). There was no significant association of chemotherapy in the last month of life with gender and tumor type (Table 2).

Half of the patients had an imaging procedure with CT, MRI, or PET- CT in the last month of life. Forty-two patients $(11.3 \%)$ had PET-CT imaging. The indication for PET-CT was staging in 21 patients, and evaluation of treatment response in 21 patients. However, having a PET-CT scan did not affect the decision of chemotherapy in the last month of life $(\mathrm{p}=0.461)$.

Median time between the last chemotherapy and death was 15 days for the patients who had chemotherapy in the last month of their life. Time between last chemotherapy and death was significantly shorter in newly diagnosed patients (median 12.4 days, range 1-58) compared to other patients (median 25 days, range $0-168)(\mathrm{p}=0.006)$.

\section{Discussion}

This study showed that $23.9 \%$ of patients received chemotherapy during the last month of life, while $10.5 \%$ of patients were treated during the last 14 days. Median duration between the last course of chemotherapy and death was 15 days (range 1-30) in the subgroup of the patients who had chemotherapy in the last month of life.

There are various reports in the literature from different parts of the world concerning chemotherapy usage near the end of life. Although the heterogeneity of study populations and design makes direct comparison difficult, the percentage of our patients who had chemotherapy in the last month of life $(23.9 \%)$ was higher than the reported numbers of 9 to $23 \%$ [3,11-17]. However, there were studies that had reported higher rates of chemotherapy in the last month of life varying between $31-55.6 \%$ [18-21]. In our study, $10.5 \%$ of patients had chemotherapy in the last 14 days of life. Different rates of chemotherapy in the last 14 days were reported in the literature varying between 


\section{Table 1 Patient characteristics}

\begin{tabular}{|c|c|}
\hline Characteristic n(\%) & \\
\hline \multicolumn{2}{|l|}{ Age } \\
\hline$<65$ years old & $240(64.3 \%)$ \\
\hline$\geq 65$ years old & $133(35.7 \%)$ \\
\hline \multicolumn{2}{|l|}{ Sex } \\
\hline Men & $229(61.4 \%)$ \\
\hline Women & $144(38.6 \%)$ \\
\hline \multicolumn{2}{|l|}{ Tumor type } \\
\hline NSCLC & $95(25.5)$ \\
\hline Pancreas and biliary tract & $42(11.3 \%)$ \\
\hline Gastric-esophagus & $32(8.6 \%)$ \\
\hline Colon-rectum & $32(8.6 \%)$ \\
\hline Gynecologic & $28(7.5 \%)$ \\
\hline Breast & $25(6.7 \%)$ \\
\hline Bladder & $15(4 \%)$ \\
\hline Prostate & $15(4 \%)$ \\
\hline Head and neck & $14(3.8 \%)$ \\
\hline $\mathrm{SCLC}$ & $14(3.8 \%)$ \\
\hline Primary X & $13(3.5 \%)$ \\
\hline Sarcoma & $11(2.9 \%)$ \\
\hline $\mathrm{RCC}$ & $10(2.7 \%)$ \\
\hline GBM & $10(2.7 \%)$ \\
\hline Testis & $5(1.3 \%)$ \\
\hline Melanoma & $4(1.1 \%)$ \\
\hline $\mathrm{HCC}$ & $4(1.1 \%)$ \\
\hline M. Mesothelioma & $3(0.8 \%)$ \\
\hline Thymic carcinoma & $1(0.3 \%)$ \\
\hline \multicolumn{2}{|l|}{ ECOG } \\
\hline 2 & $18(4.8 \%)$ \\
\hline 3 & $154(41.3 \%)$ \\
\hline 4 & $201(53.9 \%)$ \\
\hline \multicolumn{2}{|l|}{ Newly diagnosed } \\
\hline Yes & $74(19.8 \%)$ \\
\hline No & $229(80.2 \%)$ \\
\hline
\end{tabular}

Chemotherapy in the last month of life

$$
\text { Yes }
$$

No

Chemotherapy in the 14 days of life

$$
\text { Yes }
$$

No

Imaging studies in the last month of life

High cost imaging in the last month of life (CT/MRI/PET-CT)

\begin{tabular}{|c|c|}
\hline \multicolumn{2}{|c|}{ PET- $C T$ in the last month of life } \\
\hline Yes & $42(11.3 \%)$ \\
\hline No & $331(88.7 \%)$ \\
\hline \multicolumn{2}{|l|}{ Cause of death } \\
\hline Disease Progression & $303(81 \%)$ \\
\hline Renal/hepatic failure* & $18(4.8 \%)$ \\
\hline Sepsis/febril neutropenia & $33(8.8 \%)$ \\
\hline Bleeding & $12(3.2 \%)$ \\
\hline Others** & $7(1.9 \%)$ \\
\hline
\end{tabular}

Table 1 Patient characteristics (Continued)

3.7- 33.8\% [1,11-13,20-25]. Earle CC reported in his review that the proportion of patients still receiving chemotherapy within 14 days of death is on the rise. Among the 215,484 patients, $17.0 \%$ were still being treated within 2 weeks of death [26]. See Table 3 for rates of chemotherapy usage at the end of life from other countries.

Patients younger than 65 years were undergoing chemotherapy more often than those who were 65 years old or older. Age was defined as a predictor of palliative chemotherapy near the end of life in other studies [11,12,22-24]. However, age alone is not considered a contraindication for the usage of chemotherapy. Older patients may benefit from chemotherapy similar to younger ones, although they have an increased risk of toxicity [28-31]. In order to plan medical treatment in elderly patients, it is mandatory to practice a comprehensive geriatric assessment that includes evaluation of co-morbidities, functional dependence, socio-economic, emotional and cognitive conditions, an estimate of life expectancy, and recognition of frailty [30].

Newly diagnosed patients were more likely to have chemotherapy in the last month of life. One explanation for the use of chemotherapy within 1 month before death is to treat the previously untreated patients with chemosensitive tumors [32]. Of the 23 patients who were newly diagnosed and had chemotherapy in the last month, only 2 of the patients had small cell lung carcinoma, so this cannot be a possible explanation for our study group. Näppä et al. reported that $47.0 \%$ of patients who received chemotherapy within the last month were given first line palliative chemotherapy, $20 \%$ of these even at the first course of first line [14]. They explained these results with the unpredictable fast progression of disease, increased sensitivity to the side effects, and physician errors in formulating the accurate prognosis. We think one possible explanation for the use of chemotherapy within 1 month of death in newly diagnosed patients can be the feeling 'to 
Table 2 Factors associated with the use of chemotherapy in the last month of life

\begin{tabular}{|c|c|c|c|c|}
\hline \multirow[b]{2}{*}{ Risk factor } & \multicolumn{2}{|c|}{ Univariate analysis } & \multicolumn{2}{|c|}{ Multivariate analysis } \\
\hline & OR $(95 \% \mathrm{Cl})$ & $p$ value & OR $(95 \% \mathrm{Cl})$ & $p$ value \\
\hline Age group ( $<65$ years or $\geq 65$ years) & $1.95(1.14-3.34)$ & 0.015 & $1.91(1.09-3.35)$ & 0.024 \\
\hline Gender (male or female) & $1.25(0.76-2.06)$ & 0.377 & - & - \\
\hline ECOG performance score (2 or 3 or 4 ) & - & 0.009 & - & 0.034 \\
\hline (2 or 3$)$ & $4.73(1.76-12.74)$ & 0.002 & $3.78(1.37-10.38)$ & 0.010 \\
\hline (3 or 4$)$ & $1.22(0.74-2.01)$ & 0.442 & $1.08(0.64-1.81)$ & 0.770 \\
\hline Type of cancer & - & 0.784 & - & - \\
\hline Newly diagnosed (Yes or No) & $1.71(0.98-3.00)$ & 0.059 & $1.83(1.02-3.27)$ & 0.042 \\
\hline PET- CT in the last month (Yes or No) & $1.31(0.64-2.68)$ & 0.461 & - & - \\
\hline
\end{tabular}

OR: odds ratio, Cl: confidence interval, ECOG: the Eastern Cooperative Oncology Group.

give a chance' to chemotherapy; it may be easier to cease treatment in the heavily treated ones.

It has been reported that tumor type can be a predictor of chemotherapy at the end of life. Patients with breast cancer [11,20,32], lung cancer [11,32], hematologic malignancies [32], and ovarian and pancreatic tumors [20] were more likely to have chemotherapy near the end of life. There was no association between the administration of chemotherapy in the last month of life and tumor type in our study.

PET-CT is a popular imaging procedure in evaluating cancer. Forty-two patients (11.3\%) had PET-CT imaging in the last month of life. Hu et al. had reported that
$1.1 \%$ of the patients with stage IV breast, lung, colorectal and prostate cancer patients had PET-CT imaging in the last month of life [33]. Interestingly, having a PET-CT scan examination did not alter the chemotherapy decision. It may be reasonable to evaluate the treatment response with PET-CT to decide to continue, change or stop the treatment. But in patients who are not medically fit for chemotherapy staging could be done with other imaging modalities such as CT or MRI (In our country, the cost of PET-CT scan is 10 times that of a CT of thoraxabdomen). Dinan et al. reported that high cost imaging is not correlated with the de-escalation of aggressive care. Hospitals within the top quartile of imaging use

Table 3 Chemotherapy at the end of life: review of the literature

\begin{tabular}{|c|c|c|c|}
\hline Author-publication year & Country & Chemotherapy in the last month & Chemotherapy in the last 14 days \\
\hline Hu W-2013 [22] & Canada & & $3.7 \%$ \\
\hline Emanuel EJ -2003 [3] & USA & $9 \%$ & \\
\hline Zdenskowski N -2013 [15] & Australia & $12 \%$ & \\
\hline Keam B-2008 [23] & Korea & & $5.7 \%$ \\
\hline Gonçalves JF-2008 [11] & Portugal & $13 \%$ & $10 \%$ \\
\hline Adreis F-2011 [13] & Italy & $16 \%$ & $6 \%$ \\
\hline Tang ST -2009 [17] & Taiwan & $16 \%$ & \\
\hline Kao S-2009 [12] & England & $18 \%$ & $8 \%$ \\
\hline Liu TW-2012 [16] & Taiwan & $17-21 \%$ & \\
\hline Näppä -2011 [14] & Sweden & $23 \%$ & \\
\hline Göksu SS* 2014 & Turkey & $23.9 \%$ & $10.5 \%$ \\
\hline Frigeri M-2013 [27] & Switzerland & $24 \%$ & \\
\hline Yun YH-2007 [18] & Korea & $31 \%$ & \\
\hline Earle CC -2004 [1] & USA & & $15.7 \%$ \\
\hline Barbera L-2006 [24] & Canada & & $16 \%$ \\
\hline Nakano K -2012 [25] & Japan & & $20 \%$ \\
\hline Randen M -2013 [19] & Sweden & $32 \%$ & \\
\hline Braga S-2007 [20] & Portugal & $37 \%$ & $21 \%$ \\
\hline Sanz Ortiz J-2012 [21] & Spain & $55.6 \%$ & $33.8 \%$ \\
\hline
\end{tabular}

*Results of this study. 
generally had decreased odds of hospice utilization and higher likelihood of late hospice enrollment across most cancer types [8]. To our knowledge, there is no data on the cost-effectiveness of PET-CT in the terminally ill cancer patients. So physicians should think again when ordering such an expensive imaging procedure at the end of life.

Usage of chemotherapy at the end of life is also associated with the health care system. It has been reported that hospitals with a palliative care unit were significantly associated with less frequent use of chemotherapy near the end of life [15]. Patients who were not given information about palliative care and were treated by a medical oncologist continue to have chemotherapy near death $[8,34]$. The supportive and palliative care unit integration decreases the chemotherapy use in the last 30 days of life [35]. Currently there are only a few palliative care units in Turkey $[9,10]$. Most of the hospitals, even the university cancer centers, do not have a palliative care unit and patients are treated by the medical oncologists until death. As our center does not have a palliative care unit, our results should be interpreted from this view. The Turkish Ministry of Health and Cancer Control department implemented 'The Pallia-Turk Project in 2010 ' to improve the palliative care system in Turkey [9], but further work is needed to improve this system.

The present study has some limitations. First, our study was conducted in a university teaching hospital. Earle CC had previously reported that large hospital size is a strong predictor of aggressive care [26]. This situation can cause a selection bias. Second, we don't have the data of the patients who obtained palliative chemotherapy in the last month and died at home or in another hospital. By adding these patient percentages, chemotherapy use in the last month of life may be higher.

\section{Conclusion}

This is the first study that examined the use of chemotherapy at the end of life in Turkey. Chemotherapy use in the last month of life in a tertiary care center of Turkey seems to be high. Patients who were younger than 65 years old, newly diagnosed, and had good performance status were more likely to receive chemotherapy at the end of life. An aggressive approach to continue chemotherapy at the end of life has no survival benefit [36]. Instead, it may contribute to negative outcomes. Increasing the quality of life should be the first goal of treatment near the end of life and physicians should consider ceasing chemotherapy and direct the patient to palliative care center earlier.

\section{Competing interests}

The authors declare that they have no competing interests.

\section{Authors' contributions}

SSG: design, interpretation of data, writing the article, drafting the manuscript. SG: acquisition of the data, writing the article. DU: statistical analysis of the data. MU: acquisition of the data. DA: acquisition of the data. AMT: acquisition of the data. HB: revising the manuscript. MO: interpretation of data, revising the manuscript. HSC: design, interpretation of data, revising the manuscript. All authors read and approved the final manuscript.

\section{Acknowledgement}

The authors thank to Aydın Unal, MD, Erciyes University, Turkey, who helped in the analysis of the data.

\section{Author details}

${ }^{1}$ Kayseri State Hospital of Research and Education, Department of Medical Oncology, Kayseri, Turkey. ${ }^{2}$ Department of Medical Oncology, Akdeniz University, Faculty of Medicine, Antalya, Turkey. ${ }^{3}$ Kayseri State Hospital of Research and Education, Department of Radiation Oncology, Kayseri, Turkey.

Received: 22 April 2014 Accepted: 10 November 2014

Published: 19 November 2014

\section{References}

1. Earle CC, Neville BA, Landrum MB, Ayanian JZ, Block SD, Weeks JC: Trends in the aggressiveness of cancer care near the end of life. J Clin Oncol 2004, 22(2):315-321.

2. Temel JS, McCannon J, Greer JA, Jackson VA, Ostler P, Pirl WF, Lynch TJ, Billings JA: Aggressiveness of care in a prospective cohort of patients with advanced NSCLC. Cancer 2008, 113(4):826-833.

3. Emanuel EJ, Young-Xu Y, Levinsky NG, Gazelle G, Saynina O, Ash AS: Chemotherapy use among Medicare beneficiaries at the end of life. Ann Intern Med 2003, 138(8):639-643.

4. Martoni AA, Tanneberger S, Mutri V: Cancer chemotherapy near the end of life: the time has come to set guidelines for its appropriate use. Tumori 2007, 93(5):417-422.

5. Earle CC, Park ER, Lai B, Weeks JC, Ayanian JZ, Block S: Identifying potential indicators of the quality of end-of-life cancer care from administrative data. J Clin Oncol 2003, 21(6):1133-1138.

6. Earle CC, Neville BA, Landrum MB, Souza JM, Weeks JC, Block SD, Grunfeld E, Ayanian JZ: Evaluating claims-based indicators of the intensity of end-of-life cancer care. Int J Qual Health Care 2005, 17(6):505-509.

7. Yabroff KR, Warren JL: High-cost imaging in elderly patients with stage IV cancer: challenges for research, policy, and practice. J Natl Cancer Inst 2012, 104(15):1113-1114.

8. Dinan AM, Setoguchi S, Curtis LH, Cheung WY: Association between high-cost imaging and hospice use at the end of life of cancer patients[abstract]. J Clin Oncol 2013, 31(suppl):abstr 6504

9. Ozgul N, Gultekin M, Koc O, Goksel F, Bayraktar G, Ekinci H, Sencan I, Tuncer AM, Aksoy M, Tosun N: Turkish community-based palliative care model: a unique design. Ann Oncol 2012, 23(suppl 3):76-78.

10. Mutafoglu K, DEU Palliative Care Strategy Group: A palliative care initiative in Dokuz Eylul University Hospital. J Pediatr Hematol Oncol 2011, 33(suppl 1):S73-S76.

11. Gonçalves JF, Goyanes C: Use of chemotherapy at the end of life in a Portuguese oncology center. Support Care Cancer 2008, 16(4):321-327.

12. Kao S, Shafiq J, Vardy J, Adams D: Use of chemotherapy at end of life in oncology patients. Ann Oncol 2009, 20(9):1555-1559.

13. Andreis F, Rizzi A, Rota L, Meriggi F, Mazzocchi M, Zaniboni A: Chemotherapy use at the end of life. A retrospective single centre experience analysis. Tumori 2011, 97(1):30-34.

14. Näppä $U$, Lindqvist $\mathrm{O}$, Rasmussen $\mathrm{BH}$, Axelsson B: Palliative chemotherapy during the last month of life. Ann Oncol 2011, 22(11):2375-2380.

15. Zdenkowski N, Cavenagh J, Ku YC, Bisquera A, Bonaventura A: Administration of chemotherapy with palliative intent in the last 30 days of life: the balance between palliation and chemotherapy. Intern Med J 2013, 43(11):1191-1198.

16. Liu TW, Chang WC, Wang HM, Chen JS, Koong SL, Hsiao SC, Tang ST: Use of chemotherapy at the end of life among Taiwanese cancer decedents, 2001-2006. Acta Oncol 2012, 51(4):505-511.

17. Tang ST, Wu SC, Hung YN, Huang EW, Chen JS, Liu TW: Trends in quality of end-of-life care for Taiwanese cancer patients who died in 2000-2006. Ann Oncol 2009, 20(2):343-348. 
18. Yun YH, Kwak M, Park SM, Kim S, Choi JS, Lim HY, Lee CG, Choi YS, Hong YS, Kim SY, Heo DS: Chemotherapy use and associated factors among cancer patients near the end of life. Oncology 2007, 72(3-4):164-171.

19. Randén M, Helde-Frankling M, Runesdotter S, Strang P: Treatment decisions and discontinuation of palliative chemotherapy near the end-of-life, in relation to socioeconomic variables. Acta Oncol 2013, 52(6):1062-1066.

20. Braga S, Miranda A, Fonseca R, Passos-Coelho JL, Fernandes A, Costa JD, Moreira A: The aggressiveness of cancer care in the last three months of life: a retrospective single centre analysis. Psychooncology 2007, 16(9):863-868.

21. Sanz Ortiz J: Chemotherapy at the end of life: up until when? Clin Trans/ Oncol 2012, 14(9):667-674.

22. Hu W, Yasui Y, White J, Winget M: Aggressiveness of end-of-life care for patients with colorectal cancer in Alberta, Canada: 2006-2009. J Pain Symptom Manage 2014, 47(2):231-244.

23. Keam B, Oh DY, Lee SH, Kim DW, Kim MR, Im SA, Kim TY, Bang YJ, Heo DS: Aggressiveness of cancer-care near the end-of-life in Korea. Jpn J Clin Oncol 2008, 38(5):381-386.

24. Barbera L, Paszat L, Chartier C: Indicators of poor quality end-of-life cancer care in Ontario. J Palliat Care 2006, 22(1):12-17.

25. Nakano K, Yoshida T, Furutama J, Sunada S: Quality of end-of-life care forpatients with metastatic non-small-cell lung cancer in general wards and palliative care units in Japan. Support Care Cancer 2012, 20(4):883-888.

26. Earle CC, Landrum MB, Souza JM, Neville BA, Weeks JC, Ayanian JZ: Aggressiveness of cancer care near the end of life: is it a quality-of-care issue? J Clin Oncol 2008, 26(23):3860-3866.

27. Frigeri M, De Dosso S, Castillo-Fernandez O, Feuerlein $K$, Neuenschwander $H$, Saletti P: Chemotherapy in patients with advanced pancreatic cancer: too close to death? Support Care Cancer 2013, 21(1):157-163.

28. Fervers B: Chemotherapy in elderly patients with resected stage II-IIIA lung cancer. BMJ 2011, 343:d4104.

29. Turner N, Zafarana E, Becheri D, Mottino G, Biganzoli L: Breast cancer in the elderly: which lessons have we learned? Future Oncol 2013, 9(12):1871-1881.

30. Rossi A, Colantuoni G, Maione P, Ferrara C, Airoma G, Barzelloni ML, Castaldo V, Gridelli C: Chemotherapy of breast cancer in the elderly. Curr Med Chem 2005, 12(3):297-310.

31. Mcllmurray M: The medical treatment of cancer in palliative care. In Oxford Textbook of Palliative Medicine. 4th edition. Edited by Geoffrey H, Cherny NI, Christakis NA, Marie F, Stein K, Portenoy RK. New York: Oxford University Press; 2010:513-525.

32. Ho TH, Barbera L, Saskin R, Lu H, Neville BA, Earle CC: Trends in the aggressiveness of end-of-life cancer care in the universal health care system of Ontario, Canada. J Clin Oncol 2011, 29(12):1587-1591.

33. Hu YY, Kwok AC, Jiang W, Taback N, Loggers ET, Ting GV, Lipsitz SR, Weeks JC, Greenberg CC: High-cost imaging in elderly patients with stage IV cancer. J Natl Cancer Inst 2012, 104(15):1164-1172.

34. Hashimoto K, Yonemori K, Katsumata N, Hotchi M, Kouno T, Shimizu C, Tamura K, Ando M, Takeuchi M, Fujiwara Y: Factors that affect the duration of the interval between the completion of palliative chemotherapy and death. Oncologist 2009, 14(7):752-759.

35. Magarotto R, Lunardi G, Coati F, Cassandrini P, Picece V, Ferrighi S, Oliosi L, Venturini M: Reduced use of chemotherapy at the end of life in an integrated-care model of oncology and palliative care. Tumori 2011, 97(5):573-577.

36. Saito AM, Landrum MB, Neville BA, Ayanian JZ, Earle CC: The effect on survival of continuing chemotherapy to near death. BMC Palliat Care 2011, 10:14.

doi:10.1186/1472-684X-13-51

Cite this article as: Sezgin Goksu et al:: Use of chemotherapy at the end of life in Turkey. BMC Palliative Care 2014 13:51.

\section{Submit your next manuscript to BioMed Central and take full advantage of:}

- Convenient online submission

- Thorough peer review

- No space constraints or color figure charges

- Immediate publication on acceptance

- Inclusion in PubMed, CAS, Scopus and Google Scholar

- Research which is freely available for redistribution

Submit your manuscript at www.biomedcentral.com/submit
Ciomed Central 